\title{
Two Dimensional Speckle Tracking Echocardiography Assessment of Left Ventricular Remodeling in Patients After Myocardial Infarction
}

\author{
Moustafa Kamal Eldin Ibrahim, Khalied Ahmad Emam El-khashab, Tamer Mosaad Elsaed Ragab \\ Cardiology Department, Faculty of Medicine, Fayoum University, Fayoum, Egypt
}

Email address:

mki11@fayoum.edu.eg (M. K. E. Ibrahim), moustafa19688@mail.com(K. A. El-khashab), dr_tamerragab@yahoo.com (T. M. Ragab)

To cite this article:

Moustafa Kamal Eldin Ibrahim, Khalied Ahmad Emam El-khashab, Tamer Mosaad Elsaed Ragab. Two Dimensional Speckle Tracking Echocardiography Assessment of Left Ventricular Remodeling in Patients After Myocardial Infarction. Cardiology and Cardiovascular Research. Vol. 4, No. 2, 2020, pp. 59-66. doi: 10.11648/j.ccr.20200402.15

Received: March 26, 2020; Accepted: April 10, 2020; Published: April 30, 2020

\begin{abstract}
Background: Adverse left ventricular remodelling (LVR), defined as progressive ventricular dilatation, distortion of chamber shape, myocardial hypertrophy, and deteriorating function, which if uninterrupted leads to congestive heart failure (CHF) and a poor clinical outcome, begins in some patients with acute myocardial infarction (AMI) even after successful percutaneous coronary intervention (PCI). Aims: This study aims at evaluating the value of speckle tracking echocardiography in predicting LVR after successful PCI in AMI patients. Materials and Methods: Eighty-four acute myocardial infarction patients. A thorough physical examination, electrocardiography (ECG) and a complete echocardiographic assessment, including speckle tracking study, was performed two days after PCI and then a follow up echocardiography with speckle tracking study was done two months afterwards. Patients were then divided into two groups based on the presence of remodelling (R+, R-). RESULTS: at baseline study global longitudinal strain (GLS) $(-11.14 \pm 0.5$ VS $-16.78 \pm 0.4, \mathrm{P}<0.0001)$, longitudinal strain rate (LSr) $(-1.01 \pm 0.05 \mathrm{VS}-1.07 \pm 0.04, \mathrm{P}<0.0001)$, culprit longitudinal strain (CulLS) $(-9.74 \pm 0.59 \mathrm{VS}-$ $15.68 \pm 0.49, \mathrm{P}<0.0001)$, culprit longitudinal strain rate (CulLSr) $(-0.95 \pm 0.05 \mathrm{VS}-1.02 \pm 0.04, \mathrm{P}<0.0001)$ were all lower in group $\mathrm{R}+$ than in R-. In the follow up study, all strain parameters studied were significantly lower in the R+ group than R-group. The most sensitive and specific parameters were the GLS and CulLS (sensitivities of $91.7 \%$ and $95.8 \%$ respectively) and (specificities of $95 \%$ and $96.7 \%$ respectively). CONCLUSION: Our findings show that impaired indices LV deformation detected two days after successful PCI for AMI may provide predictive value in detecting LV remodelling.
\end{abstract}

Keywords: Left Ventricular Remodelling, Acute Myocardial Infarction, Speckle Tracking Echocardiography

\section{Introduction}

Improvement in the early diagnosis, invasive and medical treatment of acute myocardial infarction (AMI) lead to reduction in the mortality rates associated with early and late complications of AMI. However even complete revascularization doesn't exclude the risk of adverse left ventricular remodeling (LVR). [10].

Left ventricular remodeling is characterized by progressive enlargement and change in the shape of the LV cavity leading to systolic dysfunction. It occurs, as an adaptation to the tissue infarction, as a result of macro and microscope changes at the cardiomyocyete leading to structural and functional changes. Left ventricular remodeling is associated with worse outcomes and predisposes to heart failure [3].

Although various studies evaluated multiple clinical factors and routine echocardiographic parameters to try to detect LVR as a consequence of myocardial infarction, there are still gaps in our data, and some of the clinical factors or diagnostic parameters failed to identify patients prone to LVR [26].

Speckle tracking echocardiography (STE) is an echocardiographic method for evaluating and measuring global and regional strain, longitudinal, circumferential, radial and transverse-the precise indices of ventricle function The main advantages of speckle tracking echocardiography technique over strain assessment based on Doppler tissue imaging are that measurements are angle independent, and that it can 
distinguish active from passive movement of wall segments. Strain-based parameters have been validated in experimental and human studies as sensitive indicators of regional and global cardiac function [21].

Our aim was to evaluate the value of speckle tracking echocardiography in the prediction of left ventricular remodeling in patients after primary coronary angioplasty in acute coronary syndrome.

\section{Methods}

This study was a prospective cohort study conducted in Fayoum university hospital including patients from the emergency department and the in-patient cardiology department, after approval of research and ethical committee.

Eighty four patients diagnosed with acute myocardial infarction, either ST segment elevation myocardial infarction (STEMI) or non ST segment myocardial infarction (NSTEMI), were included. All patients underwent percutaneous coronary intervention (PCI) with stent implantation according to the ACC/AHA guidelines for STEMI and NSTEMI. Patients were then followed for two months for the occurrence of left ventricular remodeling and prediction factors including number of diseased vessels, and time to reperfusion. Patients were then divided into two groups (Remodeling $(\mathrm{R}+)$ and Non remodeling (R-)) according to the occurrence of remodeling. Inclusion criteria included typical chest pain, elevated cardiac biomarkers (Troponin and CK-MB) and then classification into ST elevation myocardial infarction or non ST segment elevation myocardial infarction was done based on the electrocardiogram.

Exclusion criteria included history of prior myocardial infarction, heart muscle disease (cardiomyopathy) with regional or global hypokinesia, valvular heart disease, significant arrhythmias (including atrial fibrillation), previous pacemaker or cardioverter defibrillator implantation, patients who have undergone coronary artery by-pass grafting or previous PCI, and very poor image quality.

All patients received best guideline directed medical therapy as per the ACC/AHA guidelines for STMEI and NSTEMI. These medications included angiotensin converting enzyme inhibitors (ACE-I), $\beta$-blockers, statins, aspirin, and ADP receptor blocker, in target doses as per the ACC/AHA guidelines.

\section{Data Entry and Statistical Analysis}

Data was collected, coded and analyzed using SPSS (Statistical Package for Social sciences) software (Version 25 ) on Windows 7, and a simple descriptive analysis in the form of percentage distribution, means and S. D. (Standard Deviation) was executed. Categorical data was analyzed by computing percentages, and consequent differences were tested statistically by applying chi square tests for comparisons between groups; students' T-test to compare between two groups, a p-value of $<0.05$ was considered statistically significant. For sensitivity and specificity a ROC curve was obtained and data were derived from it.

\section{Results}

This study was conducted on eighty four patients from the emergency department and in-patients who attended the Fayoum university teaching hospital in the duration from May 2017 till September 2018, fulfilling the inclusion and exclusion criteria and also agreed to participate in the study.

Table 1. Basic characteristics and risk factors according to remodeling $(N=84)$.

\begin{tabular}{|c|c|c|c|c|c|}
\hline \multirow{2}{*}{ Variables } & \multicolumn{2}{|c|}{ Patients with Remodeling $(\mathrm{R}+)(\mathrm{N}=24)$} & \multicolumn{2}{|c|}{ Patients without remodeling $(\mathrm{R}-)(\mathrm{N}=60)$} & \multirow{2}{*}{ P-value ${ }^{\#}$} \\
\hline & Mean & \pm SD & Mean & $\pm \mathrm{SD}$ & \\
\hline Age & 58.92 & 9.38 & 58.32 & 6.99 & 0.749 \\
\hline Variables & $\mathrm{N}$ & $\%$ & $\mathrm{~N}$ & $\%$ & P-value \\
\hline \multicolumn{6}{|l|}{ Sex } \\
\hline Male & 17 & 70.8 & 41 & 68.3 & \multirow{2}{*}{0.823} \\
\hline Female & 7 & 29.2 & 19 & 31.7 & \\
\hline \multicolumn{6}{|l|}{ Smoking } \\
\hline Yes & 15 & 62.5 & 34 & 56.7 & \multirow{2}{*}{0.624} \\
\hline No & 9 & 37.5 & 26 & 43.3 & \\
\hline \multicolumn{6}{|c|}{ Hypertension } \\
\hline Yes & 14 & 58.3 & 34 & 56.7 & \multirow{2}{*}{0.889} \\
\hline No & 10 & 41.7 & 26 & 43.3 & \\
\hline \multicolumn{6}{|l|}{ Diabetes } \\
\hline Yes & 13 & 54.2 & 29 & 48.3 & \multirow[t]{2}{*}{0.629} \\
\hline No & 11 & 45.8 & 31 & 51.7 & \\
\hline
\end{tabular}

${ }^{\#}$ Independent t-test.

${ }^{\#}$ Chi-squared $\left({ }^{2}\right)$ test.

Table 1 shows the basic characteristics and risk factors in both groups ( $\mathrm{R}+, \mathrm{R}-)$, where the mean age of $\mathrm{R}+$ group patients was $58.9 \pm 9.3$ and that of the R-group was $58.3 \pm 6.9$. In the $\mathrm{R}+$ group $70.8 \%$ were males and $29.2 \%$ were females, while in the R-group $68.3 \%$ were males and $31.7 \%$ were females.

In regards to the different risk factors, in the $\mathrm{R}+$ group $62 \%$ were smokers, $54 \%$ were diabetic and $58 \%$ were hypertensive, while in the R- group $56 \%$ were smokers, $48 \%$ were diabetic and $56 \%$ were hypertensive. 
There was no statistical significant difference between

different risk factors.

both of the groups in regards to the basic characteristics and

Table 2. Angiographic results in relation to remodeling $(N=84)$.

\begin{tabular}{llllll}
\hline \multirow{2}{*}{ Variables } & \multicolumn{2}{l}{ Patients with Remodeling (N=24) } & \multicolumn{2}{l}{ Patients without remodeling (N=60) } & \multirow{2}{*}{ P-value $^{\#}$} \\
\cline { 2 - 5 } & Mean & $\mathbf{\text { SD }}$ & Mean & \pm SD & 0.725 \\
Number of diseased vessels & 1.83 & 0.82 & 1.77 & 0.76 & $<0.0001$ \\
Time to reperfusion & 18.75 & 8.89 & 5.55 & 2.45 & P-value $^{\# \#}$ \\
Variables & $\mathrm{N}$ & $\%$ & $\mathrm{~N}$ & $\%$ & \\
IRA & & & & 48.3 & 0.868 \\
LAD & 12 & 50.0 & 29 & 21.7 & \\
LCX & 4 & 16.7 & 13 & 30.0 & \\
RCA & 8 & 33.3 & 18 & & \\
\hline
\end{tabular}

\#Independent t-test.

${ }^{\#}$ Chi-squared $\left({ }_{*}^{2}\right)$ test.

IRA- infarct related artery, LAD-Left anterior descending artery, LCX- left circumflex artery, RCA- Right coronary artery.

Table 2 Shows the angiographic results in both groups $(\mathrm{R}+$, and $\mathrm{R}-)$, where the only statistical significant difference between both groups was in the time to reperfusion which was longer in the $\mathrm{R}+$ group than in the $\mathrm{R}$ - group with means of $18.75 \pm 8.8$ hours and $5.55 \pm 2.45$ hours respectively and a $\mathrm{P}$ value of $<0.0001$.

On the other hand, there were no statistical significant difference between both groups in regards to the number of diseased vessels or the infarct related artery (IRA), where in the $\mathrm{R}+$ group $50 \%$ had the LAD as the IRA, $16 \%$ had the LCX and $33 \%$ had the RCA as the IRA. While in the Rgroup $48 \%$ had the LAD as the IRA, $21 \%$ had the LCX and $30 \%$ had the RCA as the IRA.

Table 3. Basic echocardiographic results in relation to remodeling $(N=84)$.

\begin{tabular}{|c|c|c|c|c|c|}
\hline \multirow[t]{2}{*}{ Variables } & \multicolumn{2}{|c|}{$\begin{array}{l}\text { Patients with } \\
\text { Remodeling }(\mathrm{N}=\mathbf{2 4})\end{array}$} & \multicolumn{2}{|c|}{$\begin{array}{l}\text { Patients without } \\
\text { remodeling }(\mathrm{N}=60)\end{array}$} & \multirow[t]{2}{*}{ P-value } \\
\hline & Mean & \pm SD & Mean & $\pm \mathrm{SD}$ & \\
\hline \multicolumn{6}{|c|}{ Two days after PCI } \\
\hline $\mathrm{EF}$ & 50.63 & 2.03 & 51.29 & 3.96 & 0.322 \\
\hline EDV & 87.25 & 9.04 & 89.55 & 8.15 & 0.261 \\
\hline ESV & 43.08 & 4.91 & 43.70 & 5.94 & 0.654 \\
\hline WMSI & 1.58 & 0.08 & 1.23 & 0.07 & $<0.0001$ \\
\hline \multicolumn{6}{|c|}{ After 2 months } \\
\hline $\mathrm{EF}$ & 50.67 & 2.27 & 54.81 & 4.17 & $<0.0001$ \\
\hline EDV & 106.36 & 11.32 & 87.59 & 8.23 & $<0.0001$ \\
\hline ESV & 52.46 & 6.08 & 39.69 & 5.98 & $<0.0001$ \\
\hline
\end{tabular}

"Independent t-test.

EF-ejection fraction, EDV- end diastolic volume, ESV- end systolic volume, WMSI- wall motion score index.

Table 3 shows the basic echocardiography results in both groups. In the baseline echocardiography study only the wall motion score index (WMSI) showed statistically significant difference where its value was higher in the $\mathrm{R}+$ group than in the R- group, with the means of $1.58 \pm 0.08$ and $1.23 \pm 0.07$ respectively, and a $P$ value of $<0.0001$.

The EF, EDV and ESV were less in the R+ group than in the R- group of patients in the baseline echocardiography, but there was no statistical significant difference.

The follow up echocardiography study showed that there was statistically significant difference between both groups in regards to the EF, EDV and ESV, Where the EF was less in the $\mathrm{R}+$ group than in the $\mathrm{R}$ - patients (means of 50.6 \pm 2.27 and
$54.8 \pm 4.1$, and a $\mathrm{P}$ value of $<0.0001$ ), the EDV was higher in the $\mathrm{R}+$ group than in the $\mathrm{R}$ - group (means of $106.3 \pm 11.3$ and $87.5 \pm 8.2$ respectively and a $\mathrm{P}$ value of $<0.0001$ ). the ESV was also higher in the $\mathrm{R}+$ group than in the $\mathrm{R}$ - group (with values of $52.4 \pm 6$, and $39.6 \pm 5.9$ respectively and a $P$ value of $<0.0001)$.

Table 4. Doppler results two days after PCI in relation to remodeling $(N=84)$.

\begin{tabular}{|c|c|c|c|c|c|}
\hline \multirow[t]{2}{*}{ Variables } & \multicolumn{2}{|c|}{$\begin{array}{l}\text { Patients with } \\
\text { Remodeling }(\mathrm{N}=\mathbf{2 4})\end{array}$} & \multicolumn{2}{|c|}{$\begin{array}{l}\text { Patients without } \\
\text { remodeling }(\mathrm{N}=60)\end{array}$} & \multirow[t]{2}{*}{ P-value ${ }^{\#}$} \\
\hline & Mean & \pm SD & Mean & \pm SD & \\
\hline $\mathrm{E}$ & 81.04 & 3.06 & 80.18 & 4.94 & 0.431 \\
\hline A & 67.54 & 2.57 & 74.27 & 2.52 & $<0.0001$ \\
\hline $\mathrm{E} / \mathrm{A}$ & 1.20 & 0.03 & 1.08 & 0.08 & $<0.0001$ \\
\hline DT & 151.83 & 8.82 & 183.17 & 6.83 & $<0.0001$ \\
\hline Tissue Doppler & Mean & $\pm \mathrm{SD}$ & Mean & $\pm \mathrm{SD}$ & P-value \\
\hline$e^{\prime}$ & 5.24 & 0.33 & 6.22 & 0.64 & $<0.0001$ \\
\hline$E / e^{\prime}$ & 15.52 & 1.01 & 13.02 & 1.49 & $<0.0001$ \\
\hline$a^{\prime}$ & 8.59 & 0.38 & 8.65 & 0.40 & 0.554 \\
\hline$s^{\prime}$ & 6.69 & 0.35 & 6.84 & 0.41 & 0.138 \\
\hline
\end{tabular}

\#Independent t-test.

Table 4 shows that in regards to the Doppler study done at the baseline echocardiography, there were statistically significant difference between both groups in regards to (A, $\mathrm{E} / \mathrm{A}$ and $\mathrm{DT}$ ) where the A wave was lower in the $\mathrm{R}+$ group than in the R- group (67.5 \pm 2.5 , and $74.2 \pm 2.5$ respectively with a $P$ value of $<0.0001$ ), the $E / A$ ratio was higher in the $\mathrm{R}+$ group than in the $\mathrm{R}$ - group $(1.2 \pm 0.03$, and $1.08 \pm 0.08$ respectively and a $\mathrm{P}$ value of $<0.0001)$. The DT was less in the $\mathrm{R}+$ group than in the R- group (151.8 \pm 8.8 , and 183.1 \pm 6.8 respectively, and a $P$ value of $<0.0001$ ) while there was no statistical significant difference in the $\mathrm{E}$ wave value between both groups.

In regards to the tissue Doppler study, the e' was significantly lower in the $\mathrm{R}+$ group than in the $\mathrm{R}$ - group (5.2 \pm 0.3 , and $6.2 \pm 0.6$, respectively with a $\mathrm{P}$ value of $<0.0001)$. The E/e' ratio was significantly higher in the $\mathrm{R}+$ group than in the R- group (15.5 \pm 1 , and $13.02 \pm 1.4$ respectively and a $P$ value of $<0.0001$ ).

The a' and s' values didn't show a statistically significant difference between both groups. 
Table 5. Speckle tracking echocardiography results in relation to remodeling $(N=84)$.

\begin{tabular}{|c|c|c|c|c|c|}
\hline \multirow[t]{2}{*}{ Variables } & \multicolumn{2}{|c|}{$\begin{array}{l}\text { Patients with } \\
\text { Remodeling }(\mathrm{N}=\mathbf{2 4})\end{array}$} & \multicolumn{2}{|c|}{$\begin{array}{l}\text { Patients without } \\
\text { remodeling }(\mathrm{N}=60)\end{array}$} & \multirow[t]{2}{*}{ P-value ${ }^{\#}$} \\
\hline & Mean & \pm SD & Mean & \pm SD & \\
\hline \multicolumn{6}{|c|}{ Two days after PCI } \\
\hline GLS & -11.14 & 0.59 & -16.78 & 0.49 & $<0.0001$ \\
\hline $\mathrm{LSr}$ & -1.01 & 0.05 & -1.07 & 0.04 & $<0.0001$ \\
\hline GCS & -16.62 & 0.38 & -16.71 & 0.57 & 0.492 \\
\hline $\mathrm{CSr}$ & -1.23 & 0.05 & -1.24 & 0.06 & 0.06 \\
\hline CulLS & -9.74 & 0.59 & -15.68 & 0.49 & $<0.0001$ \\
\hline CulLSr & -0.95 & 0.05 & -1.02 & 0.04 & $<0.0001$ \\
\hline \multicolumn{6}{|c|}{ After 2 months } \\
\hline GLS & -11.48 & 0.59 & -17.90 & 0.51 & $<0.0001$ \\
\hline $\mathrm{LSr}$ & -0.99 & 0.05 & -1.14 & 0.04 & $<0.0001$ \\
\hline GCS & -17.03 & 0.39 & -17.32 & 0.57 & 0.023 \\
\hline $\mathrm{CSr}$ & -1.26 & 0.05 & -1.29 & 0.06 & 0.010 \\
\hline CulLS & -10.14 & 0.59 & -16.63 & 0.49 & $<0.0001$ \\
\hline CulLSr & -0.96 & 0.08 & -1.10 & 0.04 & $<0.0001$ \\
\hline
\end{tabular}

${ }^{\#}$ Independent t-test.

GLS-global longitudinal strain, LSr-Longitudinal strain rate, GCS- global circumferential strain, CSr- circumferential strain rate, CulLS- culprit longitudinal strain, CulLSr- culprit longitudinal strain rate.

Table 5 shows the speckle tracking echocardiography data from baseline and follow up studies.

In the baseline study, there was a statistically significant difference in the following values:

1. The global longitudinal strain (GLS) was lower in the $\mathrm{R}+$ group than in the R- group (means of $-11.14 \pm 0.59$, and $-16.78 \pm 0.49$ respectively, and a $\mathrm{P}$ value of $<0.0001)$.

2. The Longitudinal strain rate (LSr) was lower in the $\mathrm{R}+$ group than in the R- group (means of $-1.01 \pm 0.05$, and $1.07 \pm 0.04$ respectively and a $P$ value of $<0.0001$ ).

3. The culprit longitudinal strain (CulLS) was lower in the $\mathrm{R}+$ group than in the R- group (means of $-9.74 \pm 0.59$, and $-15.68 \pm 0.49$ respectively and $\mathrm{P}$ value of $<0.0001)$.

4. The culprit longitudinal strain rate (CulLSr) was lower in the $\mathrm{R}+$ group than in the $\mathrm{R}$ - group (means of $0.95 \pm 0.05$, and $-1.02 \pm 0.04$, respectively and $P$ value of $<0.0001)$.

But the global circumferential strain and the circumferential strain rate didn't show a statistically significant difference between both groups.

In the follow up LV deformation study done after 2 months, all the parameters showed statistically significant difference, where;

1. The Global longitudinal strain was lower in the $\mathrm{R}+$ group than in the R- group (means of $-11.48 \pm 0.59$, and $17.9 \pm 0.51$ respectively with $\mathrm{P}$ value of $<0.0001)$.

2. The longitudinal strain rate was lower in the $\mathrm{R}+$ group than in the R- group (means of $-0.99 \pm 0.05$ and $1.14 \pm 0.04$ respectively with $P$ value of $<0.0001$ ).

3. The Global circumferential strain was lower in the $\mathrm{R}+$ group than in the R- group (means of $-17.03 \pm 0.39$ and $17.32 \pm 0.57$ respectively with $P$ value of $<0.023$ ).

4. The circumferential strain rate was lower in the $\mathrm{R}+$ group than in the R- group (means of $-1.26 \pm 0.05$ and $1.29 \pm 0.06$ respectively with $P$ value of $<0.01$ ).

5. The culprit longitudinal strain was lower in the $\mathrm{R}+$ group than in the R- group (means of $-10.14 \pm 0.59$ and $16.63 \pm 0.49$ respectively with $P$ value of $<0.0001)$.

6 . The culprit longitudinal strain rate was lower in the $\mathrm{R}+$ group than in the R- group (means of $-0.96 \pm 0.08$ and $1.1 \pm 0.04$ respectively with $\mathrm{P}$ value of $<0.0001)$.

Table 6. Echocardiographic parameters at baseline study predicting LV remodeling in the 2-months follow-up.

\begin{tabular}{|c|c|c|c|c|}
\hline & $\mathbf{A U C}$ & Cut off point & Sensitivity\% & Specificity\% \\
\hline \multicolumn{5}{|c|}{ Doppler 2 days after PCI } \\
\hline A & 0.832 & 70.5 & 79.2 & 80 \\
\hline $\mathrm{E} / \mathrm{A}$ & 0.815 & 1.15 & 79.2 & 86.3 \\
\hline $\mathrm{e}^{\prime}$ & 0.883 & 5.55 & 75 & 81.3 \\
\hline $\mathrm{E} / \mathrm{e}^{\prime}$ & 0.813 & 13.69 & 83.3 & 68.3 \\
\hline DT & 0.930 & 172.5 & 87.5 & 90 \\
\hline \multicolumn{5}{|c|}{ Strain Echo 2 days after PCI } \\
\hline GLS & 0.890 & -14.0 & 91.7 & 95 \\
\hline $\mathrm{LSr}$ & 0.825 & -1.06 & 83.3 & 65.0 \\
\hline CulLS & 0.951 & -12.0 & 95.8 & 96.7 \\
\hline CulLSr & 0.873 & -0.99 & 83.3 & 73.3 \\
\hline WMSI & 0.957 & 1.4 & 87.5 & 93.3 \\
\hline
\end{tabular}

DT-Deceleration timeGLS-global longitudinal strain, LSr-Longitudinal strain rate, CulLS-culprit longitudinal strain, CulLSr-culprit longitudinal strain rate, WMSI-wall motion score index.

Table 6 show the receiver operating characteristics curves of variables from the baseline echocardiography done two days after PCI that showed significant difference between the remodeling and non -remodeling groups.

The most sensitive and specific parameters were the Culprit longitudinal strain (CulLS) and the global longitudinal strain (GLS) where both showed sensitivities of $95.8 \%$ and $91.7 \%$ respectively, and specificities of $96.7 \%$ and $95 \%$ respectively.

Out of the non-strain derived parameters, the WMSI and the DT showed the highest specificity, where the specificities were $90 \%$ and $93.3 \%$ respectively.

\section{Discussion}

Adverse ventricular remodelling occurs after myocardial infarction (MI) due to loss of viable myocardium, inflammatory response, increased wall stress at the border zones of the infarction and neuro-hormonal activation. Adverse remodelling is characterized by regional and global structural and functional changes in the heart. The term "adverse" refers both to the changes from a hemodynamic standpoint and to the negative prognostic implications of the process [22]. Due to the progress in the field of percutaneous coronary intervention, the incidence and extent of adverse ventricular remodelling have significantly declined. Acute inhospital MI mortality has markedly decreased, and therefore the majority of MI survivors have preserved left ventricular (LV) systolic function and excellent 1-year survival rate. Patients who experience adverse ventricular remodelling suffer a significantly higher in-hospital and short-term 
mortality [27].

\subsection{Prevalence of Adverse Ventricular Remodelling}

The goal of this study was to analyse the prevalence, clinical characteristics, and predictors of left ventricular remodelling after acute myocardial infarction in the era of primary percutaneous coronary intervention and modern medical therapy. Despite aggressive treatment, including reperfusion and anti-remodelling strategies, ventricular enlargement is still common. Our study shows that out of the eighty-four patients with AMI, twenty-four patients (30\%) suffered from left ventricular remodelling defined as $\geq 20 \%$ increase in the end diastolic or end systolic volumes of the LV on follow up echocardiography, in comparison to the baseline echocardiography. In a study done by Liszka et al, 2014, adverse LV remodelling was detected in $27 \%$ of the AMI population of the study. In a meta-analysis by Huttin et al 2016, including 23 prospective studies, it was found that despite the high success rate of revascularization by PCI, adverse LV remodelling occurred in one third of the patients following AMI (12 to 44\%). The variability in the prevalence of remodelling between our study and other studies, although minor, may be due to differences in study populations, and timing of imaging [19, 15].

Therefore, despite modern treatment, our data suggest that ventricular remodelling remains a frequent event. It is important to consider that adequate reperfusion in patients with acute myocardial infarction salvages myocardium and reduces mortality. However, successful restoration of epicardial coronary patency doesn't always cause adequate reperfusion at the microvascular level (phenomenon of noreflow) [9]

\subsection{Time to Reperfusion}

Our study shows that there was a significant longer mean time from first symptoms occurrence to reperfusion in the subgroup of AMI patients who suffered from adverse LV remodeling, where the mean duration was 18.75 hours \pm 8.89 versus 5.55 hours \pm 2.45 in the non-remodeling subgroup, with a $\mathrm{P}$ value of $<0.0001$. This result is comparable to the results of a study done by Hsiao et al, 2016, in which the door to balloon time was longer in the remodeling group. Also this same finding was detected by Liszka et al 2014, but other studies done by Bolognese et al 2002 and cerisano et al 1999, didn't detect such a finding $[19,5,7]$.

The first symptoms-reperfusion time consists of three parts: a) time to first medical contact, b) time to medical center and c) door to balloon time. The relatively long overall time to reperfusion found in our study was mainly due to their unnecessary emergency call delay despite clear symptoms or ambiguous and atypical general symptoms, which patients primarily did not associate with their cardiovascular system (e.g. gastrointestinal-like symptoms in inferior wall ischemia). The LVR occurring despite successful reperfusion may be a consequence of a lower rate of viable cardiomyocytes in the area of infarction unable to prevent adverse remodeling [23, 4].

\subsection{Wall Motion Score Index}

Our study shows that there was a significantly higher wall motion score index (WMSI) value in the remodeling subgroup than in the non-remodelers. This finding is comparable to the results of a study done by Loboz-Grudzien et al. 2007, which found that a WMSI value of $\geq 1.5$ was predictive of progressive left ventricular dilatation (PLVD) after myocardial infarction [20].

In a study done by Eek et al, 2010 it was found that a WMSI value of more than 1.44 indicated an infarct size of more than $12 \%$ of the myocardium (infarct size was calculated as infarct volume as a percentage of total myocardial volume as quantified by MRI) [8]. Final infarct size is a strong predictor of mortality and major adverse cardiovascular events. Current reperfusion therapy is effective resulting in a relative reduction of infarct size achieved of typically $40 \%$ by thrombolysis and $60 \%$ by primary PCI. The reduced mortality rate observed in the reperfusion era is largely attributable to reduction of final infarct size. This WMSI value is comparable to the cutoff value in our study which is 1.4 , at which both the sensitivity and specificity for the prediction of LV adverse remodeling were $87.5 \%$ and $93.3 \%$ respectively.

\subsection{Doppler Echocardiography}

In the study done by Cerisano et al, 1999 it was found that the assessment of LV filling pattern on Doppler echocardiography provides additional and important information in the setting of AMI, allowing identification of patients at high risk for progressive LV dilation after AMI. A restrictive filling pattern, as expressed by a short DT, was the most powerful predictor of LV remodeling, and the degree of $\mathrm{LV}$ dilation was related to the severity of impairment of LV filling [7].

Previous studies have demonstrated that infarct size is one of the major factors that promotes LV remodeling [11] and [24]. On the other hand, the size of the infarct zone has been shown to influence the diastolic filling pattern, with the large infarcts exhibiting a "restrictive" filling pattern. Therefore, a short DT, indicative of a restrictive filling pattern, might simply reflect an increasing infarct size and consequently a higher risk of LV dilation [25].

In agreement with the aforementioned observations, in our study the subgroup of patients with remodeling showed a significantly lower value of the A wave, shorter deceleration time and a higher E/A value. The tissue Doppler also showed a significantly lower $\mathrm{e}^{`}$ and a higher $\mathrm{E} / \mathrm{e}^{\prime}$ values in the remodeling subgroup.

Our results thus also suggest a restrictive filling pattern in the remodeling group, with the DT being the most specific Doppler parameter (at a cutoff value of $172.5 \mathrm{~ms}$, sensitivity of $87.5 \%$ and specificity of $90 \%$ ) for detection of $\mathrm{LV}$ remodeling after 2 months.

Our study thus shows that early noninvasive assessment of 
trans-mitral flow velocity by Doppler echocardiography allows identification of patients at high risk for progressive LV dilation within 2 months after reperfused AMI. A restrictive filling pattern is a powerful predictor of $\mathrm{LV}$ remodeling, with the deceleration time being the most Doppler specific parameter.

\subsection{Speckle Tracking Echocardiography Derived Strain Parameters}

Speckle tracking echocardiography derived strain parameters: There has been extensive research about global longitudinal strain (GLS), global circumferential strain (GCS) and therefore the longitudinal and circumferential strain rates ( $\mathrm{LSr}, \mathrm{CSr}$ ) and that they were proposed as predictors for reworking, however, most of them had limitation of small patient number. Some studies demonstrated that GLS may be a powerful prognosticator for reworking while other studies claimed GCS is that the best prognosticator and even other studies claimed the circumferential strain rate to be the simplest predictor of transforming. Our study shows that, out of the various strain parameters measured 2 days after the PCI, the GLS, LSr, CulLS and therefore the CulLSr were significantly lower within the subgroup of patients that afterwards suffered from adverse LV remodelling. In 2008 Park et al. demonstrated that GLS predicts remodelling. Although remodelling was defined by $>15 \%$ increase in EDV and that they targeted only anterior wall infarct with patient population of fifty. Lacalzada et al (2015) also illustrated that GLS predicts remodeling in STEMI with ninety-seven low risk patient group. albeit only 20 out of 97 patients developed remodelling therein study [18]. A large study by Joyce et al (2014) reported an association between GLS and adverse LV dilatation after STEMI in 1041 patients. The population was divided into 2 groups consistent with a median valve of GLS of $-15.0 \%$. Patients with baseline GLS less than $-15.0 \%$ exhibited greater LV dilatation at 3and 6-month follow-ups compared with patients with GLS equal or quite $-15.0 \%$. this is often almost like our study that showed that at a cutoff value of $-14 \%$, the sensitivity and specificity of GLS to predict LV remodeling were $91.7 \%$ and $95 \%$ respectively [17]. On the opposite hand, Bonios et al (2014) stated that in their research on potential predictors of $\mathrm{LV}$ remodelling in patients with acute anterior wall myocardial infarct, apical CS was a stronger predictive marker of LV remodelling as compared to LS. One potential pathophysiological explanation of this finding is that LV CS plays a more pivotal role in maintaining LV structure, which worse circumferential CS might contribute to LV remodeling [6]. In support of this hypothesis are the results of the study by Aikawa et al. (2001), where in patients with an anterior infarction apical regional wall stress was an independent predictor of subsequent LV remodelling after AMI [2]. But it's worth mentioning that in both of these studies only patients with anterior myocardial infarct were included. The VALIANT Echo study, in contrary to our study, demonstrated that circumferential strain rate was predictive for LV remodelling but that GLS and LSr weren't. That study investigated 603 patients with LV dysfunction or coronary failure after myocardial infarct. Only 311 cases had adequate image quality to allow assessment of all longitudinal and circumferential strain and strain rate. The GLS and LSRs were derived only from the mean of apical 4- and 2-chamber views. Probably, the mean valve of a complete of 12 segments wasn't representative of worldwide values. it's worth mentioning that those patients were enrolled before the systematic use of primary percutaneous coronary intervention and other guideline based anti-remodeling therapies [15]. In our study, we also investigated the culprit longitudinal strain and strain rate (CulLS, CulLSr) which were defined as the average longitudinal strains and strain rates of the territories of the culprit vessels, and both showed significant difference between the groups of remodelers and non-remodelers (both were significantly lower). These results are in partial concordance with results of the study by Hsiao et al (2016). which demonstarted that, out of both of these values, only the CulLSr showed significant difference (was significantly lower within the adverse remodeling group) [14].

Which is the best parameter for prediction of adverse LV remodeling? In our study, the CulLS and therefore the GLS (longitudinal strain parameters) were the foremost sensitive and specific parameters for the prediction of LVR with sensitives of $95.8 \%$ and $91.7 \%$ respectively and specificities of $96.7 \%$ and $95 \%$ respectively. Gjesdal et al 2008, discovered that the GLS level identified by 2D speckle tracking echocardiography is closely correlated with myocardial infarction size as determined by contrastenhanced resonance imaging during chronic ischemic heart condition. A strain value of $-15 \%$ has $83 \%$ sensitivity and $93 \%$ specificity at the worldwide level and $76 \%$ sensitivity and $95 \%$ specificity at the territorial level (territory of the culprit vessel) to spot infarction [12]. The contractility of segments within the remote zone could compensate tomaintain $\mathrm{LV}$ systolic function. We assume abnormal segments play a more important role in adverse LVR in patients with AMI [16]. This might partially explain why the CulLS in our study had a better sensitivity and specificity than the GLS. STE-derived parameters are markers of LV function which more closely reflect intrinsic and subclinical myocardial impairment than traditional parameters by assessing the active component of myocardial deformation.

\section{Limitations of the Study}

1. Our cohort of patients was relatively small, and it was limited to patients with few complications. Patients who required mechanical ventilation were difficult to be included due to poor image quality.

2. Deformation imaging based on speckle tracking technique relies on above-average image quality for good data extraction, and continuous endocardial border motion would be the major determinant in enrollment. 


\section{Conclusion}

Adverse LV remodeling occurred in $30 \%$ of AMI patients even after PCI. The 2D speckle tracking echocardiography proved to be a promising, feasible, and noninvasive modality to evaluate myocardial deformation in this cohort. In our study, CulLS and GLS were the most sensitive and specific predictors of adverse LV remodeling.

\section{Ethics}

This study was reviewed and approved by the Fayoum University-Faculty of Medicine (Research Ethical Committee). The official approval was obtained from the general director of hospital and the manager of the outpatient clinic and the head of the Cardiology department.

\section{Consent to Participate}

The study was performed after explaining its objectives and confidentiality was expressed to the participants. Written consent was taken from the participants as an agreement to join the study before clinical examination and laboratory investigation. All participants had the right to not participate in the study.

\section{Declaration}

The authors declare that this manuscript did not previously publish or considered for publication in any other journal. The authors do not hold any stocks or shares, fees, funding or salary from any organization that may in any way gain or lose financially from the publication of this manuscript, either now or in the future.

\section{Competing Interests}

There is no conflict of interest as there are no commercial or financial relationships from any institution or organization that could be construed as a potential conflict and all the expenses are covered by the authors.

\section{Consent to Publish}

Not applicable.

\section{Availability of Data and Materials}

All the data are available on an excel sheet and also SPSS format and if needed the corresponding author is welcome to send it upon request.

\section{References}

[1] Abate E, Hoogslag GE, Leong DP, et al. 2014: Association between multilayer left ventricular rotational mechanics and the development of left ventricular remodeling after acute myocardial infarction. J Am Soc Echocardiogr. Mar; 27 (3): 239-48.
[2] Aikawa Y, Rohde L, Plehn J, et al. (2001) Regional wall stress predicts ventricular remodeling after anteroseptal myocardial infarction in the Healing and Early Afterload Reducing Trial (HEART): an echocardiography-based structural analysis. Am Heart J. 141: 234-242.

[3] Arnold SV, Spertus JA, Masoudi FA, et al. (2013): Beyond medication prescription as performance measures: optimal secondary prevention medication dosing after acute myocardial infarction, J Am Coll Cardiol 62: 17911801 .

[4] Bertini M, Mollema SA, Delgado V, et al 2009: Impact of time to reperfusion after acute myocardial infarction on myocardial damage assessed by left ventricular longitudinal strain. Am J Cardiol; 104: 480-5.

[5] Bolognese L, Neskovic A, Parodi G (2002): Left ventricular remodeling after primary coronary angioplasty. Circulation; 106: 2351-7.

[6] Bonios MJ, Kaladaridou A, Tasoulis A, et al (2014): Value of apical circumferential strain in the early post-myocardial infarction period for prediction of left ventricular remodeling. Hellenic J Cardiol. Jul Aug; 55 (4): 305-12.

[7] Cerisano G, Bolognese L, Carrabba N, et al (1999). Dopplerderived mitral deceleration time. An early strong predictor of left ventricular remodeling after reperfused anterior acute myocardial infarction. Circulation; 99: 230-6.

[8] Eek C, Grenne B, Brunvand H, et al 2010: Strain echocardiography and wall motion score index predicts final infarct size in patients with non-ST-segment-elevation myocardial infarction. Circ Cardiovasc Imaging. Mar; 3 (2): 187-94.

[9] Farah E, Cogni AL, Minicucci MF, et al. (2012): Prevalence and predictors of ventricular remodeling after anterior myocardial infarction in the era of modern medical therapy. Med Sci Monit; 18 (5): CR276-81.

[10] Funaro S, Galiuto L, Boccalini F, et al. (2011): Determinants of microvascular damage recovery after acute myocardial infarction: Results from the Acute Myocardial Infarction Contrast Imaging (AMICI) multi-centre study, Eur J Echocardiogr 12 (4): 306-312.

[11] Gaudron P, Eilles C, Kugler I, et al. 1993 Progressive left ventricular dysfunction and remodeling after myocardial infarction: potential mechanisms and early predictors. Circulation; 87: 755-763.

[12] Gjesdal O, Helle-Valle T, Hopp E, et al. (2008): Noninvasive separation of large, medium, and small myocardial infarcts in survivors of reperfused ST-elevation myocardial infarction: a comprehensive tissue Doppler and speckle-tracking echocardiography study. Circ Cardiovasc Imaging. Nov; 1 (3): 189-96.

[13] Grabka M, Wita K, Tabor Z, et al. (2013): Prediction of infarct size by speckle tracking echocardiography in patients with anterior myocardial infarction. Coron Artery Dis. 2013 Mar; 24 (2): 127-34.

[14] Hsiao J-F, Chung C-M, Chu C-M, et al. (2016) TwoDimensional Speckle Tracking Echocardiography Predict Left Ventricular Remodeling after Acute Myocardial Infarction in Patients with Preserved Ejection Fraction. PLoS ONE 11 (12): e0168109. doi: 10.1371/journal. pone. 0168109 . 
[15] Huttin O, Coiro S, Selton-Suty C, et al. (2016) Prediction of Left Ventricular Remodeling after a Myocardial Infarction: Role of Myocardial Deformation: A Systematic Review and Meta Analysis. PLoS ONE 11 (12): e0168349. doi: 10.1371/journal. pone.0168349.

[16] Ingul CB, Malm S, Refsdal E, et al. 2010: Recovery of function after acute myocardial infarction evaluated by tissue Doppler strain and strain rate. J Am Soc Echocardiogr. Apr; 23 (4): 432-8.

[17] Joyce E, Hoogslag GE, Leong DP, et al. (2014): Association between left ventricular global longitudinal strain and adverse left ventricular dilatation after ST-segment-elevation myocardial infarction. Circ Cardiovasc Imaging. Jan; 7 (1): 74-81.

[18] Lacalzada J, de la Rosa A, Izquierdo MM, et al. (2015): Left ventricular global longitudinal systolic strain predicts adverse remodeling and subsequent cardiac events in patients with acute myocardial infarction treated with primary percutaneous coronary intervention. Int J Cardiovasc Imaging; 31: 575-84.

[19] Liszka J, Haberka M, Tabor Z, et al. (2013): Two dimensional speckle tracking echocardiography assessment of left ventricular remodeling in patients after myocardial infarction and primary reperfusion. Arch Med Sci 6 (10): 1091-1100.

[20] Loboz-Grudzien k, Kowalska A, Brzezinska B, et al 2007: Early predictors of adverse left ventricular remodelling after myocardial infarction treated by primary angioplasty. Cardiol J; 14 (3): 238-45.
[21] Marwick TH, Leano RL, Brown J, et al. (2009) Myocardial strain measurement with 2-dimensional speckle-tracking echocardiography: definition of normal range. JACC Cardiovasc Imaging. 2 (1): 80-4.

[22] Na HM, Cho GY, Lee JM, et al. 2016: Echocardiographic Predictors for Left Ventricular Remodeling after Acute ST Elevation Myocardial Infarction with Low Risk Group: Speckle Tracking Analysis. J Cardiovasc Ultrasound. Jun; 24 (2): 128-34.

[23] Nicolosi GL, Golcea S, Ceconi C 2009: Effects of perindopril on cardiac remodeling and prognostic value of pre-discharge quantitative echocardiographic parameters in elderly patients after acute myocardial infarction: the PREAMI echo substudy. Eur Heart J; 30: 1656-65.

[24] Pipilis A, Meyer TE, Ormerod D, et al. 1992. Early and late changes in left ventricular filling after acute myocardial infarction and the effect of infarct size. Am J Cardiol.; 70: $1397-1401$

[25] Popovic AD, Neskovic AN, Marinkovic J, et al 1996: Serial assessment of left ventricular chamber stiffness after acute myocardial infarction. Am J Cardiol.; 77: 361-364.

[26] Seropian IM, Sonnino C, Van Tassell BW, et al. (2015): Inflammatory markers in ST-elevation acute myocardial infarction, Eur Heart J Acute Cardiovasc Care.

[27] Takemura G, Nakagawa M, Kanamori H, et al. (2009): Benefits of reperfusion beyond infarct size limitation. Cardiovasc Res. 2009 Jul 15; 83 (2): 269-76. 